\title{
New bioelectrical impedance formula for patients with respiratory insufficiency: comparison to dual-energy X-ray absorptiometry
}

\author{
U.G. Kyle*, C. Pichard*, T. Rochat**, D.O. Slosman+, J-W. Fitting**, D. Thiebaud ${ }^{+}$
}

New bioelectrical impedance formula for patients with respiratory insufficiency: comparison to dual-energy X-ray absorptiometry. U.G. Kyle, C. Pichard, T. Rochat, D.O. Slosman, J-W. Fitting, D. Thiebaud. CERS Journals Ltd 1998.

ABSTRACT: Malnutrition in patients with severe respiratory insufficiency can lead to severe complications, justifying the use of objective nutritional assessment techniques, such as bioelectrical impedance analysis (BIA), which is an easy, noninvasive method of measuring body composition. The purpose of this study was to develop, and validate against dual-energy X-ray absorptiometry (DXA), a BIA formula to predict fat-free mass (FFM) specific for patients with chronic severe respiratory insufficiency.

Seventy-five ambulatory patients ( 15 females and 60 males) with severe chronic respiratory insufficiency (obstructive and restrictive) aged 63.6 \pm 19.2 yrs (mean $\pm \mathrm{sD}$ ), in a stable pulmonary and cardiac condition for $\mathbf{S} 2$ months, were measured simultaneously with BIA and DXA. Patients younger than 45 yrs of age and with a body mass index $\mathbf{S} 32 \mathrm{~kg} \cdot \mathrm{m}^{-2}$ were excluded.

The best-fitting multiple regression equation to predict $\mathrm{FFM}=\mathbf{- 6 . 0 6}+($ height $\times$ $\mathbf{0 . 2 8 3})+($ weight $\times \mathbf{0 . 2 0 7})-($ resistance $\times \mathbf{0 . 0 2 4})+($ sex $($ males $=1$, females $=0) \times 4.036)$, gave a correlation coefficient of $r=0.952$, slope \pm SEM $0.902 \pm 0.034$, standard error of the estimate 1.670, and $p<0.0001$. The mean difference for $F F M$ was $0.2 \pm 2.3 \mathrm{~kg}$ (mean \pm sD) and percentage fat mass was $\mathbf{- 0 . 7 \pm 3 . 8 \%}$.

These results suggest that the bioelectrical impedance analysis formula specific to patients with severe respiratory insufficiency give a better correlation and smaller mean differences than 12 different bioelectrical impedance analysis formulae described in the medical literature. A prediction equation, validated against dual-energy $\mathrm{X}$-ray absorptiometry and based on subjects with similar clinical characteristics, is more applicable to the patients with respiratory insufficiency than a formula developed for healthy subjects.

Eur Respir J 1998; 12: 960-966.

Severe respiratory insufficiency causes patients to be intolerant of physical effort and to be frequently limited in their daily activity and results in an imbalance between food intake and nutritional needs. Undernutrition and overnutrition can both affect the quality of life and survival of patients with pulmonary disease. Protein-energy malnutrition can lead to quantitative, qualitative and functional alterations of muscle $[1,2]$ and this affects muscle function, including respiratory muscle in patients with already limited respiratory reserves. Optimal adaptation of nutrition support through the assessment of fat-free mass (FFM) and fat mass (FM) in patients with chronic respiratory insufficiency can avoid or minimize muscle wasting or obesity. For these reasons, the nutritional assessment should include body composition measurements which are based on objective rather than subjective criteria of nutritional evaluation. Body composition can be measured by a number of techniques, including hydrodensitometry, isotope dilution, and whole-body counting of potassium-40 [3]. However, these methods are not easily applicable in ill subjects.

More recent methods for the determination of the FFM are dual-energy X-ray absorptiometry (DXA) and bioelec-
Divisions of $*$ Clinical Nutrition and $* *$ Pneumology and +Nuclear Medicine, University Hospitals, Geneva and Lausanne, Switzerland.

Correspondence: C. Pichard

Clinical Nutrition

Geneva University Hospital

1211 Geneva

Switzerland

Fax: 41223729363

Keywords: Bioelectrical impedance analysis bioelectrical impedance analysis-measured fat-free mass

dual-energy X-ray absorptiometry

fat-free mass

respiratory insufficiency

Received: May 71997

Accepted after revision March 101998 trical impedance analysis (BIA). DXA has been validated against independent methods, including a gamma neutronactivation model $[4,5]$, total body potassium and hydrodensitometry [6] and is becoming one of the reference methods for body composition analysis, but requires sophisticated technology. BIA is a method of measuring body composition which is easy, noninvasive and inexpensive [7]. BIA measurements have been validated in healthy adults [8-10]. The relationship between body impedance and body composition is dependent on age and sex [11, 12]. Over 20 different formulae permit the calculation of the FFM and FM based on BIA measurements and have generally been validated in healthy, young adults. Scногs et al. [13] proposed a BIA formula validated against deuterium dilution for patients with chronic obstructive pulmonary disease (COPD) $(n=24)$, which included weight and height $\mathrm{t}^{2} /$ resistance $\left(h t^{2} / R\right)$ as independent variables. Recently, PICHARD et al. [14] were unable to obtain clinically relevant correlations between FFM calculated by 12 BIA formulae [8, 9, 11, 15-21], including Schогs et al. [13], and DXA-determined FFM, and suggested that a specific formula should be developed for patients with chronic severe respiratory insufficiency. 
The purpose of this study was to develop a specific BIA formula for patients $>45$ yrs old with chronic severe respiratory insufficiency. A validated specific BIA formula would allow the use of BIA for the sequential evaluation of lean tissue and fat reserves and of evolutional changes in these parameters in these patients.

\section{Subjects and methods}

\section{Subjects}

Seventy-five ambulatory patients (15 females and 60 males) with severe chronic respiratory insufficiency in a stable clinical condition, aged 45-86 yrs, were included in this study. Table 1 shows the physical characteristics and diagnoses of the patients. Because pulmonary diseases of young patients with respiratory insufficiency are usually different (e.g. cystic fibrosis and myopathies) and patients have different characteristics (table 1), patients under 45 yrs of age were excluded. Nearly $79 \%$ of the present patients suffer from COPD. Reviews of the incidence in COPD have shown a male predominance of up to 10:1 in this disease [22] and therefore, fewer females than males were included in this study. Because errors in prediction of FM by BIA are increased in obese subjects [23], patients with a body mass index (BMI) $>32 \mathrm{~kg} \cdot \mathrm{m}^{-2}$ were also excluded. Fifty-nine of the patients were diagnosed with COPD. The remainder were patients with restrictive pulmonary disease secondary to tuberculosis or kyphoscoliosis. Patients with COPD, kyphoscoliosis and post-tuberculosis syndrome have been shown to have increased cost of breathing and increased resting energy expenditure [24] and are therefore at high risk for wasting of peripheral and respiratory muscles. It was felt that these patients could be pooled for body composition purposes. Patients with symptomatic oedema and fluid retention (as determined by a positive sign during pressure on the ankle or a gain of body weight $\mathrm{S} 1$ $\mathrm{kg}$ during the last week) were excluded to minimize errors in the prediction equation due to abnormal hydration levels. Extracellular fluid retention is possible with $\mathrm{CO}_{2}$ retention in these patients; however, the patients were in a stable (nondecompensated) condition for a period of Š2 months. Thirty-six per cent of the patients were under

Table 1. - Physical characteristics and diagnosis of the study group

\begin{tabular}{lccc}
\hline & $\begin{array}{c}\text { Females } \\
\mathrm{n}=15\end{array}$ & $\begin{array}{c}\text { Males } \\
\mathrm{n}=60\end{array}$ & \multicolumn{1}{c}{ All } \\
$\mathrm{n}=75$
\end{tabular}

Values are shown as mean \pm SD. BMI: body mass index (weight/ height ${ }^{2}$ ); COPD: chronic obstructive pulmonary disease; FEV1: forced expiratory volume in one second; $\mathrm{PO}_{2}$ : oxygen tension; $\mathrm{PCO}_{2}$ : carbon dioxide tension. home oxygen therapy. The patients' pulmonary characteristics are shown in table 1. Patients with cardiovascular, endocrine and neurological diseases were excluded. Maintenance medication included theophylline, inhaled or oral corticosteroids and $\beta$-agonists (10\% of patients). Patients who chronically received steroids ( $>20 \mathrm{mg}$ prednisone) or diuretics were excluded. Height, weight, BIA and DXA measurements were obtained during the same clinic visit to ensure that the measurements were comparable.

\section{Anthropometric measurements and bioelectrical impedance}

Body height was measured to the nearest $0.5 \mathrm{~cm}$ and body weight to the nearest $0.1 \mathrm{~kg}$ on a balance beam scale. BIA was used to determine FFM and FM as previously described $[8,10,15,25,26]$. Estimates are made of body composition from whole-body bioelectrical impedance, $V$ $=\rho \times h t^{2} / R$, in which the conductive volume $(V)$ is assumed to represent FFM, $\rho$ is the specific resistivity of the conductor, height $(h t)$ is taken as the length of the conductor, and whole-body resistance $(R)$ is measured with four surface electrodes placed on the wrist and ankle. Thus, the volume of FFM is directly proportional to $h t^{2} / R$. In brief, an electrical current of $50 \mathrm{kHz}$ and $0.8 \mathrm{~mA}$ was produced by a generator (Bio-Z®; New Cardiocorp, Fribourg, Switzerland) and applied to the skin using adhesive electrodes (Sentry Silver Sircuit@; Sentry Medical Products, Irvine, CA, USA) placed on all right side-limbs with the patient in decubitus dorsalis as described previously [27]. The Bio-Z® generator has been cross-validated against the RJL-109 $\AA$ and 101® analysers (RJL Systems, Clinton, MI, USA) and at $50 \mathrm{kHz}$ against the Xitron ${ }^{\circledR}$ analyser (Xitron Technologies, San Diego, CA, USA). The crossvalidation produced results of $\pm 5 \Omega$ for the resistance and can therefore be considered equivalent. Short-term and long-term reliability of resistance measurements indicate coefficients of variation of $1.8-2.9 \%[15,28]$. The skin was cleaned with $70 \%$ alcohol. Age, sex, height, weight, resistance and reactance were used as independent variables to predict FFM and FM as compared to DXA-derived FFM and FM.

\section{Dual-energy X-ray absorptiometry}

The DXA-based technique for body composition measurement requires: 1) general assumptions inherent in the body compartment approach (i.e. soft tissue = body weight - skeletal mass, and soft tissue $=$ fat + water-equivalent tissue), and 2) specific assumptions (soft tissue overlying bone cannot be sampled and its composition has to be extrapolated from the composition of adjacent tissue). DXA is a scanning technique which measures the differential attenuation of two different energy level X-rays as they pass through the body. These measurements allow the determination of bone mineral content and soft tissue mass on a pixel-per-pixel basis. Then, the soft tissue mass is partitioned into fat and nonfat lean body mass by a calibration procedure based on the attenuation of the soft tissue outside the bone and the attenuation of an external dedicated phantom $[29,30]$. The advantage is that the method permits, in a few minutes, the derivation of the total FM directly rather than by subtracting the other body compartments [4]. The reproducibility of the measurements is 
excellent: $1.2 \%$ for the total FFM and FM [31, 32] and $0.5 \%$ for the bone mineral content. The FM derived from DXA measurements correlates well with FM determined by hydrodensitometry and total body ${ }^{40} \mathrm{~K}$ measurements $[4,29,32,33]$. An advantage of DXA over hydrodensitometry, total body potassium and water dilution is that it can provide information about the composition of body segments and muscle mass and the distribution of fat between trunk and limbs [34]. All measurements were performed using Hologic CDR-2000® (Hologic, Waltham, MA, USA, Enhanced Whole-body 5.54 software version).

\section{Statistical analysis}

Results are expressed as mean \pm SD. Multiple regressions were calculated to test correlations between DXA and the various independent variables (sex, age, height, weight, resistance, reactance, $\left.h t^{2} / R\right)$ to predict FFM by BIA. BLAND and Altman [35] analysis was used to compare the FFM results generated by DXA to those of BIA. The differences between the values are plotted against the DXA-derived FFM. This analysis allows the calculation of the bias (estimated by the mean differences) and the limits of agreement (two standard deviations of the difference) [35]. Statistical significance was set at $\mathrm{p}<0.05$ for all tests.

\section{Results}

Table 1 summarizes the physical characteristics, diagnoses and pulmonary functions of the study group. The patients had a mean age of $65.6 \pm 9.1 \mathrm{yrs}$, weight of $54.6 \pm$ $9.8 \mathrm{~kg}$ and BMI of $19.3 \pm 3.7 \mathrm{~kg} \cdot \mathrm{m}^{-2}$, which is below the normal range for this age of population.

Table 2 shows the results of the five different multiregression calculations for FFM and FM by BIA compared to DXA in males, females and both groups combined.

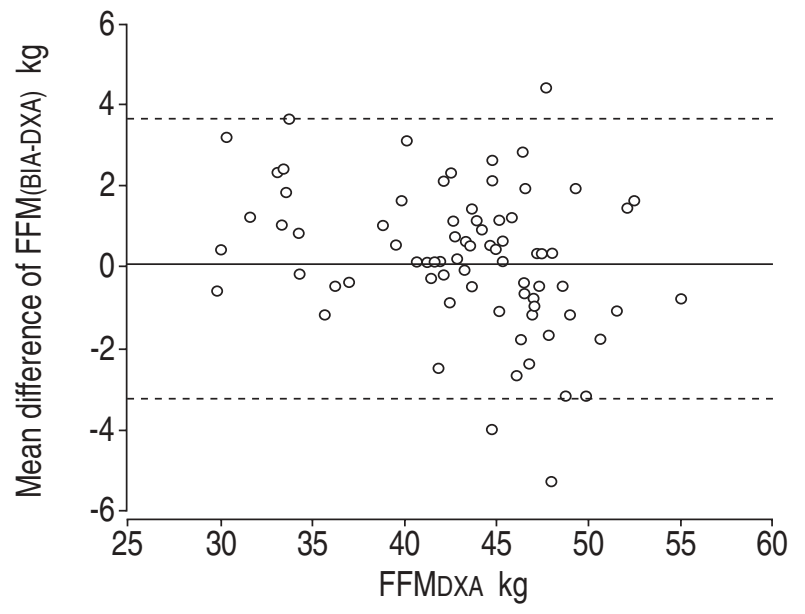

Fig. 1. - Bland-Altman plot. The mean difference of fat-free mass (FFM) (bioelectrical impedance analysis (BIA) minus dual-energy X-ray absorptiometry (DXA)) is plotted against the FFMDXA. The mean difference $(-)$ and its limits of agreement $\left( \pm 2 \mathrm{SD} ;--_{-}\right)$are shown.

Various combinations of dependent variables including age, height, weight, resistance, reactance and $h t^{2} / R$ were used to determine the best fit. The best correlation coefficients for FFM were obtained when the parameters age, height, weight, resistance and reactance, and sex if males and females were combined, were included (males $\mathrm{r}=0.93$, females $r=0.96$, both sexes $r=0.95$ ). Slightly lower correlation coefficients were noted for females $(r=0.95)$ when age (not shown), and age and reactance were eliminated. Using $h t^{2} / R$ in place of height and resistance decreased the performance of the multiple regressions (males $\mathrm{r}=0.88$, females $r=0.89$, both sexes $r=0.93$ ), lowered the slope of the regression and increased the SEE from $1.48 \mathrm{~kg}$ (ma-les), $1.53 \mathrm{~kg}$ (females) and $1.67 \mathrm{~kg}$ (both sexes) to $1.75 \mathrm{~kg}$ (males), $2.17 \mathrm{~kg}$ (females) and $1.94 \mathrm{~kg}$ (both sexes). Elimination of weight from the multiple regression further decreased the performance of the various regressions. While multiple regression calculations can predict FM well when

Table 2. - Correlations, slope and standard error of the estimate (SEE) for fat-free mass (FFM) and fat mass (FM) measured by bioelectrical impedance analysis (BIA) or dual-energy X-ray absorptiometry (DXA)

\begin{tabular}{|c|c|c|c|c|c|c|c|c|}
\hline \multirow[t]{2}{*}{ BIA formula variables } & \multicolumn{4}{|c|}{ FFM } & \multicolumn{4}{|c|}{ FM } \\
\hline & $\mathrm{r}$ & slope \pm SEM & $\begin{array}{l}\text { SEE } \\
\mathrm{kg}\end{array}$ & $\begin{array}{c}\mathrm{TE} \\
\mathrm{kg}\end{array}$ & $\mathrm{r}$ & slope \pm SEM & $\begin{array}{l}\text { SEE } \\
\mathrm{kg}\end{array}$ & $\begin{array}{c}\mathrm{TE} \\
\mathrm{kg}\end{array}$ \\
\hline \multicolumn{9}{|l|}{ Both sexes $(n=75)$} \\
\hline Age, sex, ht, wt, R, Xc & 0.95 & $0.91 \pm 0.03$ & 1.67 & 1.73 & 0.98 & $0.95 \pm 0.03$ & 1.70 & 1.72 \\
\hline Sex, ht, wt, R & 0.95 & $0.90 \pm 0.03$ & 1.67 & 1.75 & 0.98 & $0.95 \pm 0.03$ & 1.72 & 1.76 \\
\hline Sex, wt, ht ${ }^{2}, \mathrm{R}$ & 0.93 & $0.87 \pm 0.04$ & 1.94 & 2.06 & 0.97 & $0.93 \pm 0.03$ & 2.02 & 2.06 \\
\hline Sex, ht, R, Xc & 0.90 & $0.81 \pm 0.05$ & 2.25 & 2.47 & 0.55 & $0.30 \pm 0.05$ & 3.67 & 6.59 \\
\hline Sex, ht $2 / R, X c$ & 0.86 & $0.74 \pm 0.05$ & 2.53 & 2.88 & 0.55 & $0.30 \pm 0.05$ & 3.67 & 6.60 \\
\hline \multicolumn{9}{|l|}{ Males $(n=60)$} \\
\hline Age, ht, wt, R, Xc & 0.93 & $0.87 \pm 0.04$ & 1.41 & 1.50 & 0.98 & $0.95 \pm 0.03$ & 1.48 & 1.51 \\
\hline $\mathrm{Ht}$, wt, R & 0.93 & $0.86 \pm 0.46$ & 1.48 & 1.57 & 0.97 & $0.95 \pm 0.03$ & 1.55 & 1.56 \\
\hline $\mathrm{Wt}, \mathrm{ht} / \mathrm{R}$ & 0.88 & $0.78 \pm 0.05$ & 1.75 & 1.96 & 0.96 & $0.92 \pm 0.04$ & 1.91 & 1.96 \\
\hline $\mathrm{Ht}, \mathrm{R}, \mathrm{Xc}$ & 0.88 & $0.78 \pm 0.05$ & 1.75 & 1.95 & $0.44 * *$ & $0.19 \pm 0.05$ & 2.74 & 6.10 \\
\hline $\mathrm{Ht} 2 / \mathrm{R}, \mathrm{Xc}$ & 0.78 & $0.61 \pm 0.06$ & 2.05 & 2.60 & $0.39 * *$ & $0.15 \pm 0.05$ & 2.46 & 6.27 \\
\hline \multicolumn{9}{|l|}{ Females $(n=15)$} \\
\hline Age, ht, wt, R, Xc & 0.96 & $0.92 \pm 0.08$ & 1.49 & 1.49 & 0.99 & $0.97 \pm 0.05$ & 1.51 & 1.51 \\
\hline Ht, wt, R & 0.95 & $0.91 \pm 0.08$ & 1.53 & 1.52 & 0.98 & $0.97 \pm 0.05$ & 1.60 & 1.60 \\
\hline $\mathrm{Wt}, \mathrm{ht} / \mathrm{R}$ & 0.89 & $0.79 \pm 0.11$ & 2.17 & 2.28 & 0.97 & $0.93 \pm 0.07$ & 2.36 & 2.28 \\
\hline $\mathrm{Ht}, \mathrm{R}, \mathrm{Xc}$ & 0.65 & $0.42 \pm 0.14$ & 2.65 & 3.83 & 0.67 & $0.46 \pm 0.14$ & 4.63 & 6.37 \\
\hline $\mathrm{Ht}^{2} / \mathrm{R}, \mathrm{Xc}$ & 0.51 & $1.14 \pm 0.54$ & 2.71 & 3.75 & $0.45^{\dagger}$ & $0.20 \pm 0.11$ & 3.62 & 7.71 \\
\hline
\end{tabular}

ht: height; wt: weight; R: resistance; Xc: reactance. Total error ( others $\mathrm{p}<0.0001$. 
Table 3. - Comparison of fat-free (FFM) and fat (FM) mass as measured by bioelectrical impedance analysis (BIA) and dual-energy X-ray absorptiometry (DXA)

\begin{tabular}{|c|c|c|c|c|c|c|}
\hline & \multicolumn{2}{|c|}{ Females $(n=15)$} & \multicolumn{2}{|c|}{ Males $(n=60)$} & \multicolumn{2}{|c|}{ All $(n=75)$} \\
\hline & BIA & DXA & BIA & DXA & BIA & DXA \\
\hline Resistance $\Omega$ & $577.3 \pm 88.0$ & & $522.8 \pm 83.7$ & & $533.7 \pm 86.7$ & \\
\hline Reactance $\Omega$ & $64.7 \pm 16.9$ & & $63.3 \pm 19.9$ & & $63.6 \pm 19.2$ & \\
\hline FFM kg & $36.0 \pm 4.0$ & $35.8 \pm 5.2$ & $45.1 \pm 3.9$ & $44.9 \pm 4.2$ & $43.3 \pm 5.4$ & $43.1 \pm 5.7$ \\
\hline $\mathrm{FM} \mathrm{kg}$ & $17.7 \pm 9.7$ & $17.9 \pm 8.9$ & $9.7 \pm 6.7$ & $9.9 \pm 6.9$ & $11.3 \pm 7.8$ & $11.5 \pm 7.9$ \\
\hline$\% \mathrm{FM}$ & $31.1 \pm 10.8$ & $31.8 \pm 10.4$ & $16.7 \pm 7.4$ & $17.0 \pm 7.7$ & $19.5 \pm 9.7$ & $19.9 \pm 10.2$ \\
\hline Difference FFM(BIA-DXA) kg & \multicolumn{2}{|c|}{$0.2 \pm 2.3$} & \multicolumn{2}{|c|}{$0.2 \pm 1.6$} & \multicolumn{2}{|c|}{$0.2 \pm 1.8$} \\
\hline Difference \% FM(BIA-DXA) & \multicolumn{2}{|c|}{$-0.7 \pm 3.8$} & \multicolumn{2}{|c|}{$-0.3 \pm 3.0$} & \multicolumn{2}{|c|}{$-0.4 \pm 3.1$} \\
\hline
\end{tabular}

Values are shown as mean \pm SD.

four or more dependent variables are used, the prediction of FM is not considered to be reliable. BIA measures total body water and electrolytes and extrapolates FM from the difference between weight and FFM. Therefore, the multiple regression formula which included sex, height, weight and resistance was chosen to predict the FFM in males and females grouped together as follows: FFM $=-6.06+$ $($ height $\times 0.283)+($ weight $\times 0.207)-($ resistance $\times 0.024)+$ $($ sex $($ males $=1$, females $=0) \times 4.036)$ giving a correlation coefficient of $\mathrm{r}=0.952$.

Figure 1 shows the mean difference of FFM plotted against the DXA-derived FFM, including the limits of agreement of \pm 2 SD of $3.3 \mathrm{~kg}$.

Table 3 shows the results of the comparison of the FFM and FM as measured by BIA and DXA, including a mean difference in FFM of $0.2 \pm 1.8 \mathrm{~kg}$ and a mean difference of $-0.4 \pm 3.1 \%$ FM. The mean differences between BIA and DXA were small and equal in both sexes.

\section{Discussion}

With the availability of portable BIA machines, the clinical use of BIA has markedly increased in recent years and has facilitated the assessment of nutritional status of healthy and ill individuals. A progressive change in body composition is anticipated in patients with chronic respiratory diseases with increasing age, progression of the disease, severe disability and lack of mobility. The precision of formulae published in the literature, however, depends on a number of factors, including age and state of hydration. The purpose of this study was to determine the best regression equation for the prediction of FFM determined by BIA in comparison to DXA-derived FFM in patients with severe chronic respiratory insufficiency.

\section{Patient population}

Patients had a severe chronic ventilatory insufficiency (mean forced expiratory volume in one second $(\mathrm{FEV} 1)=$ $36.2 \pm 13.0 \%$ of predicted) and suffered from obstructive or restrictive pulmonary diseases, with various consequences on their nutritional status. Nutritional assessment by BIA or DXA is desirable because it permits the detection of low FFM in patients who may not be significantly below ideal body weight, but who have an excess of FM that may mask protein malnutrition. Given that a large portion of the population studied was underweight, this validation is limited. Indeed, most of the subjects in this study had a low BMI and could be reasonably well detected as being undernourished by height, weight, age and sex alone. Severely obese patients (BMI Š $32 \mathrm{~kg} \cdot \mathrm{m}^{-2}$ ) were excluded from the study to eliminate a possible methodological bias introduced by excessive FM in obese patients [21, 23]. Half of the subjects included in this study were underweight, with a BMI of $\partial 18.5 \mathrm{~kg} \cdot \mathrm{m}^{-2}$, and a few of the subjects were overweight (BMI 27-32 $\mathrm{kg} \cdot \mathrm{m}^{-2}$ ). Such a distribution reflects the usual body weight in a population of respiratory insufficiency and adds further value to the study results.

Fewer females were included in the study, because fewer females subjects with respiratory insufficiency presented themselves to the outpatient clinic and it has been shown that the incidence of COPD has a male predominance of up to $10: 1$ [22].

\section{Comparison of two methods of body composition}

The rationale was to compare two different methods for measuring body composition that measure independent parameters, i.e. electrical variation (BIA) versus photon absorption (DXA). BIA has been cross-validated with hydrodensitometry [9], skinfold measurements [36, 37] and deuterium dilution in healthy subjects $[38,39]$. Disease and body composition compartments that deviate from normal may result in changes that invalidate the prediction equations derived from healthy adults with normal weight [40]. Therefore, prediction equations for this subgroup of respiratory patients should be validated.

PICHARD et al. [14] tested 12 different prediction equations $[8,9,11,13,15-21]$ from the medical literature in a group of patients with respiratory insufficiency and found that correlation coefficients varied from $\mathrm{r}=0.66$ to 0.94 with variations in mean FFM of $-1.9-+8.0 \mathrm{~kg}$ [14]. Such variations preclude clinical utilization. The COPD-specific formula by Schols et al. [13], which included 24 males and 8 females, correlated $h t^{2} / R$ to deuterium-determined total body water. Their formula overestimated the FFM by $5.1 \pm 3.1 \mathrm{~kg}$ in females and by $3.8 \pm 3.1 \mathrm{~kg}$ in males, with similar pathologies to the patients in the study by PICHARD $e t$ al. [14]. Their patient sample may have been too small to control adequately for patient variability. SEGAL et al. [9] and $\mathrm{V}_{\text {AN }}$ LOAN and MAYcLI [17] noted sex differences in FFM and FM. Sex-based formulae appear to improve the prediction of BIA [41]. The lack of concordance noted between the results of S S et al. [14] is also likely to be due to the different validation criteria (deuterium dilution versus DXA). 
The best-fit prediction equation for this group of respiratory insufficiency patients was: FFM $=-6.06+$ (height $\times 0.283)+($ weight $\times 0.207)-($ resistance $\times 0.024)+($ sex (males $=1$, females $=0) \times 4.036$ ), with $\mathrm{r}=0.952$. The prediction equation developed in this study has an SEE of 1.67 $\mathrm{kg}$ and can be considered ideal as rated according to the system reported by HoutKo0per et al. [42]. Patients with BMI Š32 $\mathrm{kg} \cdot \mathrm{m}^{-2}$ were excluded because the degree of variation in FM is greater in more obese individuals and leads to greater prediction errors $[21,23]$.

\section{Variables influencing prediction accuracy of bioelectrical impedance analysis equations}

HOUTKOOPER et al. [42] noted $h t^{2} / R$ to be the best single predictor of body composition. The addition of other independent variables such as age and sex was thought to adjust for the geometric complexity of the human body and helped to improve the fit of the prediction model. Because sex has been shown to be a factor that influences FFM and FM, the males and females were examined separately [9]. However, the goal was to combine the males and females if this was justified by the results of the analysis. For practical application of the BIA in the clinical setting, it would be an advantage to have only one equation, as long as the prediction ability of the equation is not compromised.

In the present subjects the best prediction equation for FFM was obtained when height, weight, age, resistance, reactance and sex (if males and females were combined) $(\mathrm{r}=0.95, \mathrm{SEE}=1.67 \mathrm{~kg})$ were included. Age and reactance, however, did not significantly influence the prediction equation ( $p=0.44$ and 0.32 , respectively). Therefore the prediction equation chosen was the one that included height, weight, resistance and sex as independent variables. Resistance by itself was not a good predictor of body composition $(\mathrm{r}=0.52, \mathrm{SEE}=4.9 \mathrm{~kg})$, because it is not an indicator of body size or volume. However, when resistance was combined with height $(\mathrm{r}=0.88$, $\mathrm{SEE}=2.7 \mathrm{~kg})$, it predicted $\mathrm{FFM}$ better than height and weight $(\mathrm{r}=0.81, \mathrm{SEE}=3.4 \mathrm{~kg})$ and $h t^{2} / R$ $(\mathrm{r}=0.82, \mathrm{SEE}=3.3 \mathrm{~kg})$ (data not shown). STOLARCZYK et al. [21] found that prediction equations which included weight as well as height ${ }^{2}$ and resistance as independent variables improved the prediction accuracy of BIA. This was confirmed in the present study $(\mathrm{r}=0.93$ and $0.95, \mathrm{SEE}=1.67$ and $1.94 \mathrm{~kg}$, respectively). Prediction formulae that included $h t^{2} / R$ with or without weight and resistance and reactance without weight decreased the prediction accuracy of BIA in all three groups (males, females and both sexes combined).

The predictive capacity of BIA using height, weight, resistance and sex for FM was excellent in males and females, separately or combined, in this study; however, the use of BIA to predict FM is not recommended. BIA measures body conductivity based on water and electrolyte content, appears to be quantitatively related to lean mass and measures FM neither quantitatively (kg of fat) nor qualitatively (fat as a percentage of total body weight [9]. Since arms and legs contribute approximately $80 \%$ of resistance and reactance, it is possible that the FM could be underestimated in older subjects with primarily truncal fat accumulation.
No attempt was made to predict total body water, since isotope dilution studies were not used in the subjects of this study. Variations in hydration could affect the predictive capacity of BIA formulae. In haemodialysis and intensive care patients, it has been noted that excess intracellular or extracellular fluid causes an overestimation of the total body water. When the hydration level of the FFM is $>73 \%$, BIA overestimates the FFM and underestimates the FM. In these patients, BIA no longer permits accurate estimation of FFM with prediction equations that were developed for healthy subjects with normal hydration levels. Patients with visible oedema and fluid retention were excluded to minimize errors as a result of hydration status. All patients were in a clinically stable state (no decompensation for $\breve{S} 2$ months). While it is possible that the subjects in this study differed in hydration state and therefore in body density from the normal population, an attempt was made to have excluded patients with excess fluid of $>1 \mathrm{~L}$ and error due to abnormal hydration levels was minimized.

\section{Dual-energy X-ray absorptiometry}

Although DXA is not yet considered to be "the" gold standard for measuring body composition, it is one of the best reference methods [43]. DXA estimates the FM without making assumptions related to lean mass, potassium concentration or density, which are the basis of traditional methods, such as underwater weight, total body potassium and total body water techniques [44]. DXA measures the soft tissue and bone mass independently and then separates the soft tissue into lean mass and FM. There remains, however, some discussion about comparability of different hardware and software, and previous studies have noted that caution must be exercised when making comparisons between studies if different hardware and software versions have been used [45-47]. TотніLL et al. [46] found that percentage FM measured by Hologic DXA was not significantly different from that obtained by underwater weighing. They also noted that Hologic instruments re-ported lower FM than Lunar and Norland DXA. SNEAD et al. [47] suggested that DXA underestimates the percentage FM in older and obese subjects, owing to an underestimation of truncal fat [47]. Hologic Enhanced Version 5.54 software was used in this study. In a number of measurements it was found that the percentage FM was $2.2 \pm 3.6 \%$ greater with this software version than with a previous version (whole-body 5.35). Therefore the problem of underestimation of FM appears to have been corrected with newer versions of the Hologic software.

A limitation of DXA is that it does not measure total body water separately from the FFM. Therefore excess body hydration would result in overestimation of the FFM, as is noted with BIA. Further validation studies in ill subjects using DXA as a criterion measure should simultaneously measure water compartments (i.e. deuterium oxide dilution) to determine abnormalities in hydration state.

Sixty-eight per cent of patients in this study with respiratory insufficiency walked $<1,000 \mathrm{~m} \cdot$ day $^{-1}$, as assessed by a podometer (unpublished data). Subjects with similar heights and weights have different quantities of FFM and FM depending on the amount of physical activity tolerated 
by individual patients. PICHARD et al. [48] found that BIA formulae that resulted in excellent correlations in normal healthy controls resulted in poor correlations in elite runners and vice versa. It is, therefore, possible that the validity of BIA formulas depends on the degree of activity rather than on pathology. Further research into the validation of BIA should, therefore, look at ambulatory capacity in ill subjects and investigate whether physical activity must be considered as a factor in choosing the prediction equation for estimating the FFM and FM in subjects, regardless of primary diagnosis.

\section{Study limitations}

A limitation of this study was the relatively small subject pool. In addition, the statistical analysis used population-based concepts which are not directly applicable to individual subjects. Further validation is necessary to confirm the robustness of the proposed equation.

\section{Conclusions}

The present results suggest that bioelectrical impedance analysis, a simple and noninvasive procedure, is relevant in the clinical assessment of body composition of patients with severe respiratory insufficiency when using a prediction equation based on subjects with similar characteristics. The best-fitting multiple regression equation to predict fat-free mass included height, weight, resistance and sex. The present prediction equation should be used with caution in individuals younger than $45 \mathrm{yrs}$ of age and with a body mass index $\breve{S} 32 \mathrm{~kg} \cdot \mathrm{m}^{-2}$.

Acknowledgements: The authors are indebted to P. Wagner and G. Conicella for technical assistance.

\section{References}

1. Arora NS, Rochester DF. Respiratory muscle strength and maximal voluntary ventilation in undernourished patients. Am Rev Respir Dis 1982; 126: 5-8.

2. Pichard C, Hoshino E, Allard J, Charlton MP, Atwood $\mathrm{HL}$, Jeejeebhoy KN. Intracellular potassium activity and membrane potential in rat muscle during malnutrition and refeeding. Am J Clin Nutr 1991; 54: 489-498.

3. Hill GL. Body composition research: implications for the practice of clinical nutrition. J Parent Enteral Nutr 1992; 16: 197-218.

4. Heymsfield SB, Wang J, Heshka S, Kehayias JJ, Pierson RN. Dual-photon absorptiometry: comparison of bone mineral and soft tissue mass measurements in vivo with established methods. Am J Clin Nutr 1989; 49: 12831289.

5. Aloia JF, Vaswani A, Ma R, Flaster E. Comparative study of body composition by dual-energy X-ray absorptiometry. J Nucl Med 1995; 36: 1392-1397.

6. Haarbo J, Gotfredsen A, Hassager C, Christiansen C. Validation of body composition by dual energy X-ray absorptiometry (DEXA). Clin Physiol 1991; 11: 331-341.

7. Lukaski HC. Method for assessment of human body composition: traditional and new. Am J Clin Nutr 1987; 46: 537-556.
8. Lukaski HC. Validation of tetrapolar bioelectrical impedance measurements to assess human body composition. $J$ Appl Physiol 1986; 60: 1327-1332.

9. Segal KR, Van Loan M, Fitzgerald PI, Hodgdon JA, Van Itallie TB. Lean body mass estimation by bioelectrical impedance analysis: a four-site cross over validation. $\mathrm{Am}$ J Clin Nutr 1988; 47: 7-14.

10. Deurenberg P, Weststrate JA, van der Kooy K. Body composition changes assessed by biolectrical impedance measurements. Am J Clin Nutr 1989; 49: 401-403.

11. Deurenberg P, van der Kooy K, Evers P, Hulshof T. Assessment of body composition by biolectrical impedance in a population aged >60 y. Am J Clin Nutr 1990; 51: 3-6.

12. Deurenberg P, Pieters JJL, Hautvast JGAJ. The assessment of body fat percentage by skinfold thickness measurements in childhood and adolescence. Br J Nutr 1990; 63: 293-303.

13. Schols AM, Wouters EF, Soeters PB, Westerterp KR. Body composition by bioelectrical-impedance analysis compa-red with deuterium dilution and skinfold anthropometry in patients with chronic obstructive pulmonary disease. Am J Clin Nutr 1991; 53: 421-424.

14. Pichard C, Kyle UG, Janssens JP, et al. Body composition by X-ray absorptiometry and bioelectrical impedance in chronic respiratory insufficiency patients. Nutrition 1997; 13: 952-958.

15. Lukaski HC. Assessment of fat-free mass using bioelectrical impedance measurements of the human body. Am J Clin Nutr 1985; 41: 810-817.

16. Lukaski HC, Bolonchuk WW. Theory and validation of the tetrapolar bioelectrical impedance method to assess human body composition. In: Ellis KJ, Yasumura S, Morgan WD, eds. In Vivo Body Composition Studies. York, Institute of Physical Sciences in Medicine, 1987; pp. 410-414.

17. Van Loan M, Mayclin P. Bioelectrical impedance analysis: is it a reliable estimator of lean body mass and total body water? Hum Biol 1987; 2: 299-309.

18. Graves JE, Pollack ML, Calvin AB, Van Loan M, Lohman TG. Comparison of different bioelectrical impedance analyzers in the prediction of body composition. Am J Hum Biol 1989; 1: 603-611.

19. Heitmann BL. Prediction of body water and fat in adult Danes from measurement of electrical impedance: a validation. Int J Obesity 1990; 14: 417-424.

20. Deurenberg P, van der Kooy K, Leenen R, Westrate JA, Seidell JC. Sex and age specific prediction formulas for estimating body composition from bioelectrical impedance: a cross-validation study. Int J Obesity 1991; 15: 1725.

21. Stolarczyk LM, Heyward VH, Hicks VL, Baumgartner RN. Predictive accuracy of bioelectrical impedance in estimating body composition of Native American women. Am J Clin Nutr 1994; 59: 964-970.

22. Fraser RG, Paré JAP, Paré PD, Fraser RS, Genereux GP. Diagnosis of Diseases of the Chest. Philadelphia, W.B. Saunders Co., 1990; pp. 2089-2090.

23. Gray DS, Bray GA, Gemayel N, Kaplan K. Effect of obesity on bioelectrical impedance. Am J Clin Nutr 1989; 50: 255-260.

24. Sridhar MD, Carter R, Lean MEJ, Banham WS. Resting energy expenditure and nutritional state of patients with increased oxygen cost of breathing due to emphysema, scoliosis and thoracoplasty. Thorax 1994; 49: 781-785.

25. Gray DS. Changes in biolectrical impedance during fasting. Am J Clin Nutr 1988; 48: 1184-1187.

26. Deurenberg P, Weststrate JA, Paymans I, van der Kooy K. 
Factors affecting biolectrical impedance measurements in human. Eur J Clin Nutr 1988; 42: 1017-1022.

27. Kushner RF, Schoeller DA. Estimation of total body water by bioelectrical impedance analysis. Am J Clin Nutr 1986; 44: 417-424.

28. Jackson AS, Pollock ML, Graves JE, Mahar MT. Reliability and validity of bioelectrical impedance in determining body composition. J Appl Physiol 1988; 64: 529-534.

29. Slosman DO, Rizzoli R, Pichard C, Donath A, Bonjour JP. Longitudinal measurement of regional and whole body bone mass in young normal adults. Osteoporosis Int 1994; 4: 185-190.

30. Wahner WH, Fogelman I. Total body bone mineral and body composition by absorptiometry. In: Wagner WH, Fogelman I, eds. The Evaluation of Osteoporosis: Dual Energy X-ray Absorptiometry in Clinical Practice. London, Martin Dunitz, 1994; pp. 196-218.

31. Mazess RB, Barden HS, Bisek JP, Hanson J. Dual-energy $\mathrm{X}$-ray absorptiometry for total-body and regional bonemineral and soft-tissue composition. Am J Clin Nutr 1990; 51: 1106-1112.

32. Slosman DO, Casez JP, Pichard C, et al. Assessment of whole-body composition using dual X-ray absorptiometry. Radiology 1992; 185: 593-598.

33. Slosman DO, Rizzoli R, Donath A, Bonjour JP. Quantitative digital radiography and conventional dual-photon bone densitometry: study of precision at the levels of spine, femoral neck and femoral shaft. Eur J Nucl Med 1989; 185: 593-598.

34. Heymsfield SB, Smith R, Aulet M, et al. Appendicular skeletal muscle mass: measurement by dual-photon absorptiometry. Am J Clin Nutr 1990; 52: 214-218.

35. Bland JM, Altman DG. Statistical methods for assessing agreement between two methods of clinical measurement. Lancet 1986; i: 307-310.

36. Eaton AW, Israel RG, O'Brien KF, Hortobagyi T, McCammon MR. Comparison of four methods to assess body composition in women. Br J Nutr 1993; 47: 353-360.

37. Fuller NJ, Jebb SA, Goldberg GR, et al. Inter-observer variability in the measurement of body composition. Eur J Clin Nutr 1991; 45: 43-49.

38. van Marken Lichtenbelt WD, Westerterp KR, Wouters L, Luijendijk SCM. Validation of bioelectrical-impedance measurement as a method to estimate body-water compartments. Am J Clin Nutr 1994; 60: 159-166.

39. Pritchard JE, Nowson CA, Strauss BJ, Carlson JS, Kaymakci B, Wark JD. Evaluation of dual energy X-ray absorptiometry as a method of measurement of body fat. Eur J Clin Nutr 1993; 47: 216-228.

40. NIH Technology Assessment Conference Statement. Bioelectrical impedance analysis in body composition measurement: National Institutes of Health Technology Assessment Conference Statement. Am J Clin Nutr 1996; 64: Suppl., 524S-532S.

41. Deurenberg P, van der Kooy K, Leenen R, Schouten FJM. Body impedance is largely dependent on the intra- and extra-cellular water distribution. Eur J Clin Nutr 1989; 43: 845-853.

42. Houtkooper LB, Lohman TG, Going SB, Howell WH. Why bioelctrical impedance analysis should be used for estimating adposity. Am J Clin Nutr 1996; 64: Suppl., 436S-448S.

43. Van Loan MD, Mayclin PL. Body composition assessment: dual-energy X-ray absorptiometry (DEXA) compared to reference methods. Eur J Clin Nutr 1992; 46: 125-130.

44. Wellens R, Chumlea WC, Guo S, Roche AF, Reo NV, Siervogel RM. Body composition in white adults by dual energy X-ray absorptiometry, densitometry, and total body water. Eur J Clin Nutr 1993; 59: 547-555.

45. Tothill P, Avenell A, Reid DM. Precision and accuracy of measurements of whole-body bone mineral: comparisons between Hologic, Lunar and Norland dual-energy X-ray absorptiometers. Br J Radiol 1994; 67: 1210-1217.

46. Tothill P, Avenell A, Love J, Reid DM. Comparisons between Hologic, Lunar and Norland dual-energy X-ray absorptiometers and other techniques used for wholebody soft tissue measurements. Eur J Clin Nutr 1994; 48: 781-794.

47. Snead DB, Birge SJ, Kohrt WM. Age-related differences in body composition by hydrodensitometry and dualenergy X-ray absorptiometry. J Appl Physiol 1993; 74: 770-775.

48. Pichard C, Kyle U, Gremion G, Slosman D. Body composition by X-ray absorptiometry and biolelectrical impedance in elite female runners. Med Sci Sports Exerc 1997; 29: 1527-1534. 